\title{
CARANDIRU, 2009
}

\author{
Luiza Peixoto Baldan
}

O Carandiru carioca, terreno construído pela RFFSA, atualmente abriga barracões de escola de samba. Motivada pela temporalidade da ocupação daqueles galpões, tanto no tempo histórico linear como no movimento frenético durante o processo de trabalho pré-carnaval, desenvolvi projeto fotográfico concentrando-me nos resquícios encontrados que poderiam contar histórias sobre o lugar. [abstract on page 282]

CARNAVAL, BARRACÕES DE ESCOLA DE SAMBA, FOTOGRAFIA, CARANDIRU. 
É raro associar esse nome a uma cidade ou a um bairro. Carandiru é uma penitenciária em São Paulo. Pouco se sabe e pouco se vê do Carandiru carioca, um terreno construído pela RFFSA, diretamente vinculado à Estação da Leopoldina e que hoje abriga alguns barracões de escola de samba. Localizado próximo à Rodoviária Novo Rio, o complexo passa despercebido pela maioria dos que por ali circulam.

$\mathrm{Na}$ entrada principal, pessoas tomam Coca-Cola e jogam dominó em meio a carrocinhas de comida estacionadas. O mato alto cobre a linha férrea, e é preciso andar um pouco para achar os barracões. O primeiro que identifico é uma nave sem cobertura. Trata-se da estrutura restante de uma enorme oficina de trens, que dá morada também a uma família e a pelo menos oito cachorros. Dizem que Pretinha comeu o coelho.

A intempérie desbota os adereços do carnaval passado, que agora parecem ser de 1985. Tecidos em cores vivas tornam-se pastéis e, rasgados, revelam a carcaça de isopor. Mesmo decadente, a ideia de folia ainda está presente no que restou de folia, e não porque o cenário seja particularmente bonito, mas porque incita a imaginação. A sucata do ano passado serve de matéria bruta para as produções do próximo, fazendo com que a diversão nunca se acabe. Pelo contrário, somatório e acúmulo num mesmo ornamento trazem enriquecimento, pelo menos de história e memória.

Tento desvencilhar-me do aspecto negativo de qualquer definhamento. Estou interessada na temporalidade da ocupação daqueles galpões, tanto no tempo histórico linear do lugar como no movimento latente e frenético durante o processo de trabalho pré-carnaval, o que implica arruinamento e empilhamento. Penso na oficina de trem e seus funcionários que foram substituídos por barracões de escola de samba e seus carnavalescos. Penso no chão de terra que se recicla diariamente sem nunca perder uma parte de sua composição original. Penso na intensidade dos quatro meses em que todos os esforços se concentram na árdua tarefa de produzir um espetáculo com carros e fantasias complexas que serão exibidas em um só dia ou, no máximo, dois, em cerimônia que dura menos de uma hora. Penso na concentração e na dissipação da presença humana. Penso nos enfeites que ficam e no lixo que se revela quando o carro sai, deixando um desenho no chão. Penso num espaço que se contrai e que se dilata.

Detenho-me nas camadas temporais e arquitetônicas que se sobrepõem. O galpão principal é monumental, assim como a maioria dos carros e alegorias espalhados pelo interior. Parece uma fábrica de bonecos gigantes. Um mundo de ficção em que portas falsas conectam nada a lugar nenhum.

A área externa é um descampado em que plásticos, borrachas e paetês se amontoam e constroem cantos. Objetos de grande porte abandonados destacam-se como esculturas no vazio - navios naufragados e anjos. Vagões enferrujados e cobertos por mato se camuflam na paisagem, que os transforma em colinas. Uma trilha comprida leva a uma civilização distante.

Carandiru é um lugar habitado, marcado pela presença e pela acumulação de tempos, impregnado de resíduos. Busquei fotografá-lo no recesso do carnaval, concen- 
trando-me nos resquícios encontrados que poderiam contar histórias sobre o lugar. A fotografia, em sua capacidade de combinar outroras e agoras, encarna um instante, um relâmpago, apresentando uma cena em que o tempo fica em suspenso.

Luiza Baldan é mestre e bacharel em artes visuais pelo PPGAV/EBA/UFRJ e pela Florida International University (Miami, 2002) tendo recebido o XI Prêmio Marc Ferrez de Fotografia da Funarte (2010), o Color Express Award (2002) e a Brown L. \& Marion Whately Scholarship (2002).

Artigo recebido em julho de 2010 e aceito para publicação em julho 2010. 

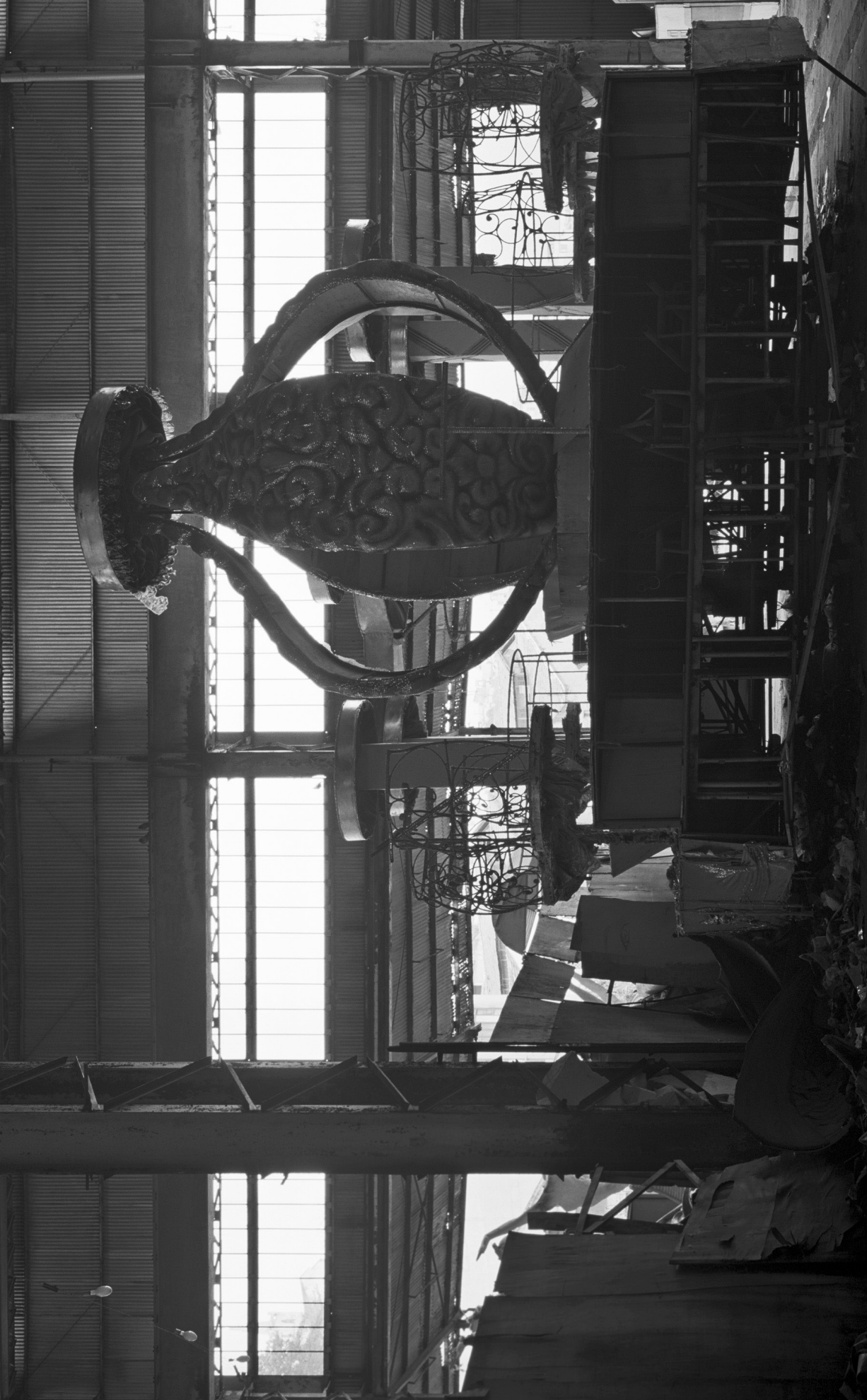


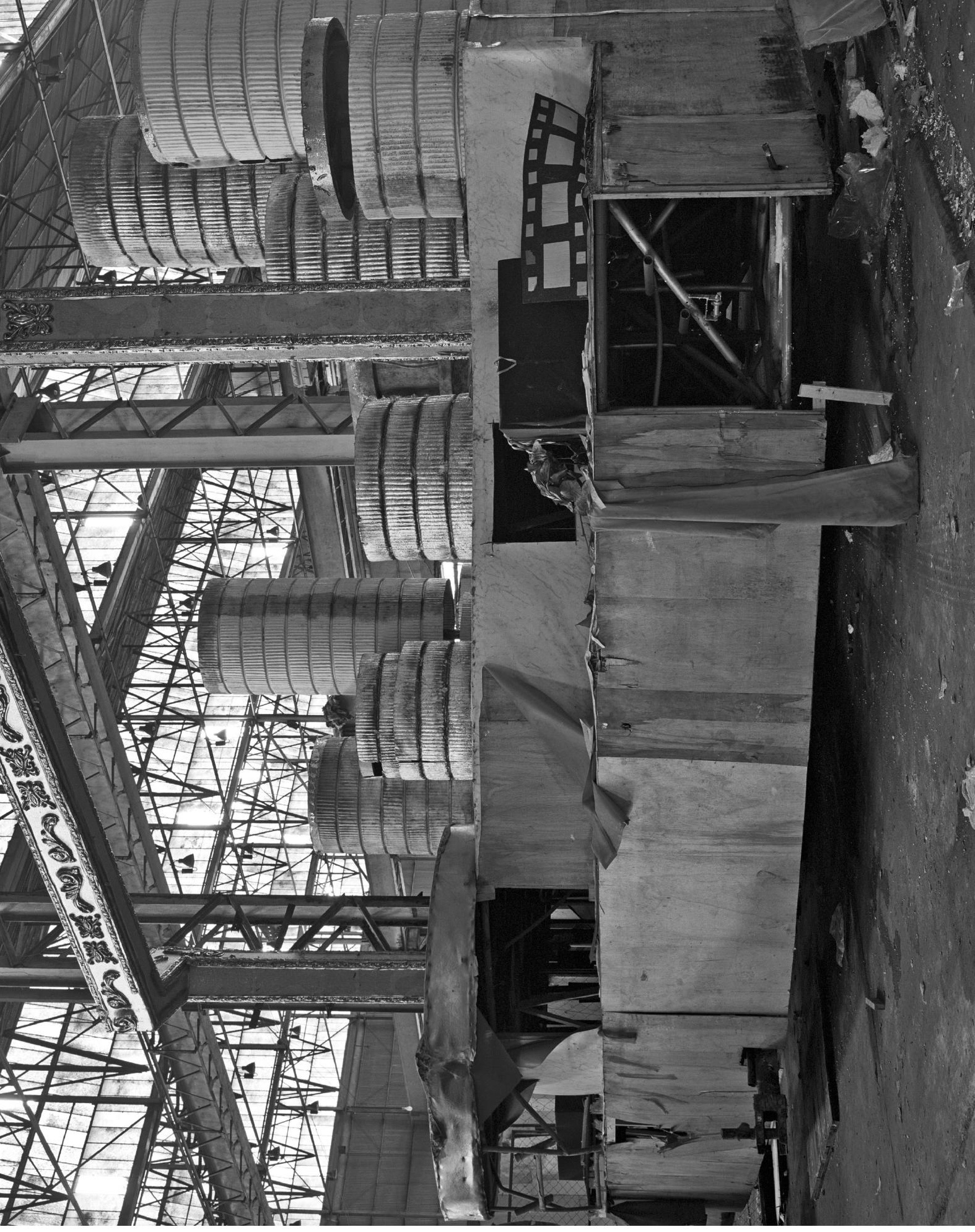




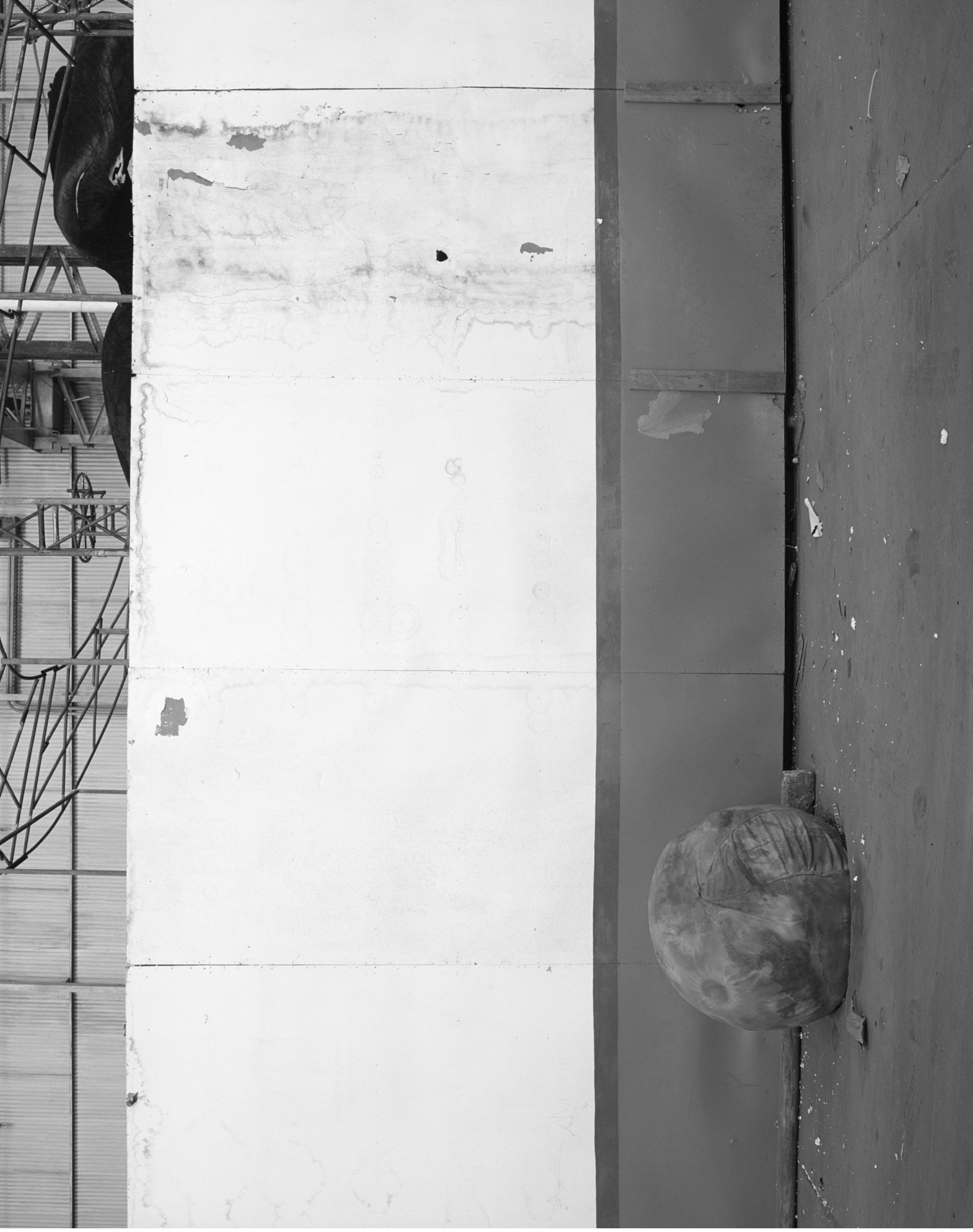




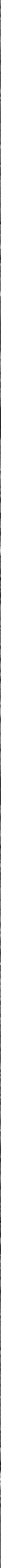




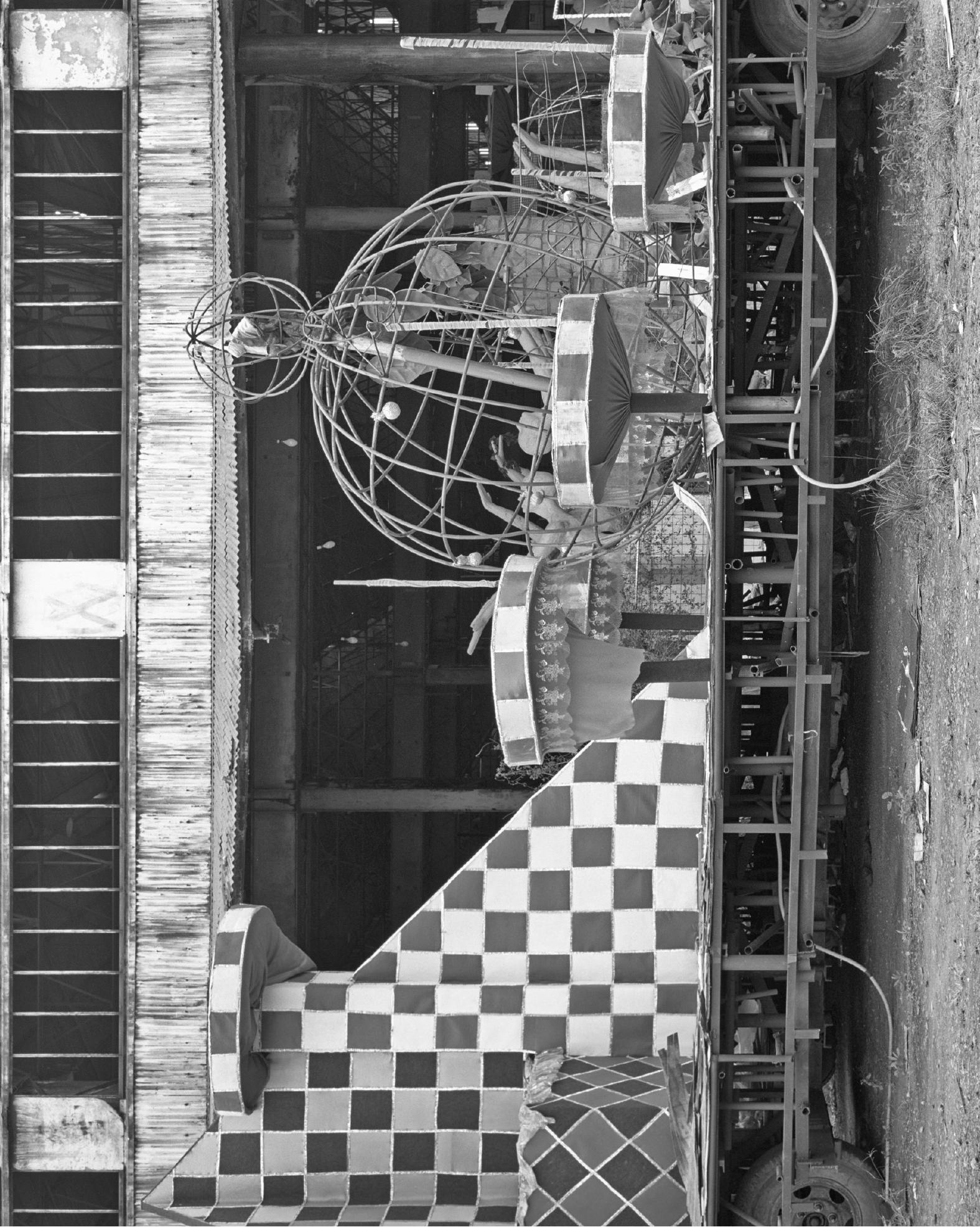



